\title{
The Pot Calling the Kettle Black: Distancing Response to Ethical Dissonance
}

\section{Citation}

Barkan, R., S. Ayal, F. Gino, and D. Ariely. "The Pot Calling the Kettle Black: Distancing Response to Ethical Dissonance." Journal of Experimental Psychology: General 141, no. 4 (2012): 757-773.

\section{Permanent link}

http://nrs.harvard.edu/urn-3:HUL.InstRepos:11320607

\section{Terms of Use}

This article was downloaded from Harvard University's DASH repository, and is made available under the terms and conditions applicable to Open Access Policy Articles, as set forth at http:// nrs.harvard.edu/urn-3:HUL.InstRepos:dash.current.terms-of-use\#OAP

\section{Share Your Story}

The Harvard community has made this article openly available.

Please share how this access benefits you. Submit a story.

\section{Accessibility}




\title{
Running Head: THE POT CALLING THE KETTLE BLACK
}

The Pot Calling the Kettle Black:

Distancing Response to Ethical Dissonance

\section{Rachel Barkan, ${ }^{1}$ Shahar Ayal, ${ }^{2,3}$ Francesca Gino, ${ }^{4}$ and Dan Ariely ${ }^{2}$}

\author{
${ }^{1}$ Ben-Gurion University of the Negev \\ ${ }^{2}$ Duke University \\ ${ }^{3}$ Interdisciplinary Center (IDC) Herzeliya \\ ${ }^{4}$ Harvard University
}

Forthcoming, Journal of Experimental Psychology: General

The authors greatly appreciate the support and facilities of the Center for Decision Research at the University of North Carolina at Chapel Hill, where the studies were conducted. The authors thank Harvard Business School, Duke University, and the Center for Decision Making at Ben-Gurion University for financial support. Please address correspondence to barkanr@som.bgu.ac.il. 


\begin{abstract}
Six studies demonstrate the "pot calling the kettle black" phenomenon whereby people are guilty of the very fault they identify in others. Recalling an undeniable ethical failure, people experience ethical dissonance between their moral values and their behavioral misconduct. Our findings indicate that to reduce ethical dissonance, individuals use a double-distancing mechanism. Using an overcompensating ethical code, they judge others more harshly and present themselves as more virtuous and ethical (Studies 1,2,3). We show this mechanism is exclusive for ethical dissonance and is not triggered by salience of ethicality (Study 4), general sense of personal failure, or ethically-neutral cognitive dissonance (Study 5). Finally, it is characterized by some boundary conditions (Study 6). We discuss the theoretical contribution of this work to research on moral regulation and ethical behavior.
\end{abstract}

Keywords: Ethical dissonance, Cognitive dissonance, Moral judgment, Self-esteem, Selfmaintenance, Impression management, Unethical behavior 


\section{The Pot Calling the Kettle Black:}

\section{Distancing Response to Ethical Dissonance}

Folk wisdom suggests that people are often guilty of the very fault they identify in others. Idioms in various languages ranging from Chinese ("The soldier that fled 50 steps mocks the one that fled 100 steps") to Portuguese ("One with torn clothes mocks the naked") imply that sinners might present themselves as overly righteous to others. A recent example of this phenomenon, which we refer to as "the pot calling the kettle black," was the forced resignation of the Massachusetts Institute of Technology (MIT) dean of admissions. The dean, known for her harsh policy toward students who puffed up their credentials or lied on their résumés, had embellished her own credentials when MIT first hired her; she had never received the bachelor's or master's degrees she claimed to have.

Is this type of compensation for one's own misdeed a general tendency? In this paper, we address this question and examine the conditions under which "the pot calling the kettle black" phenomenon is likely to occur. We propose that when people cannot deny their own misconduct, they engage in a double-distancing mechanism: using an overcompensating ethical code, they judge others more harshly and present themselves as more virtuous. Ethical Misconduct and Moral-self

Daily conduct provides many examples of ethical failures, from people standing in the express line with too many groceries, to taking home office supplies from work, or inflating business-expense reports. Research suggests that people lie and cheat much more often than they care to admit (e.g., DePaulo et al., 1996; Fischbacher \& Heusi, 2008; Gino, Ayal, \& Ariely, 2009; Mazar, Amir, \& Ariely, 2008; Tenbrunsel, Diekmann Wade-Benzoni, \& Bazerman, 2010). For example, when payment in lab experiments was based on self-report and cheating could not be detected, people tended to inflate their performance and claim 
higher payment. In a skill task, participants inflated the number of arithmetic problems they solved by $15 \%$ on average (Mazar et al., 2008). In a chance task, where payment was based on a die roll, participants lied and reported higher numbers in about $40 \%$ of the cases (Fischbacher \& Heusi, 2008; Shalvi, Dana, Handgraaf, \& De Dreu, 2011). Interestingly, in these studies, participants cheated only "by a little bit" rather than to the maximum extent possible.

At the same time, research in social psychology has consistently demonstrated that people strive to maintain a positive self-concept both privately and publicly (Adler, 1930; Allport, 1955; Jones, 1973, Rogers, 1959; Rosenberg, 1979). In fact, people strive to maintain a positive self-image even when doing so requires a degree of self-deception, pretense, or guile (Schlenker, 1982; Tajfel, 1982). Moral values are a central component of a person's positive self-image (Chaiken, Giner-Sorolla, \& Chen, 1996). People desire to perceive themselves as honest and deserving, and strongly believe in their own morality (Greenwald 1980; Sanitioso, Kunda, \& Fong, 1990). For instance, about $84 \%$ of the respondents in a study with large samples of adolescents, university students, and adults reported being moral and considered their morality to be central to their private and public identities (Aquino \& Reed, 2002).

The conflicting cognitions involving dishonest behavior on the one hand and belief in a positive moral self on the other hand pose a threat to well-being and require tensionreduction mechanisms.

\section{$\underline{\text { Solving Ethical Inconsistencies }}$}

Recently, scholars have explained the existence of these ethical inconsistencies with bounded ethicality, a term referring to a range of cognitive limitations and systematic biases operating beneath awareness and blinding people to their own misconduct (Banaji, Bazerman, \& Chugh, 2003; Chugh, Bazerman, \& Banaji, 2005). These biases might change 
the meaning of the committed behavior, emphasize attenuating circumstances of context and situational factors, or soften the person's moral standards. For example, although individuals might easily recall worthy behavior, unethical incidents might "disappear" from their memory (Baumeister \& Newman, 1994; Shu \& Gino, 2012). Such processes help people dismiss unethical behavior, reinforce a sense of consistency between behavior and desired moral standards, and sustain a positive self-image (Kunda, 1990; Lydon, Zanna, \& Ross, 1988; Ross, McFarland, Conway, \& Zanna, 1983).

Even when people recognize their ethical inconsistencies, there are various ways to redefine unethical behavior as morally acceptable or at least as not entirely unethical. For example, participants can interpret not cheating to the maximum extent as maintaining ethicality or as resisting obvious temptations presented by the researchers (Mazar et al., 2008). As another example, they can reframe taking a newspaper without paying the full price as paying something despite the absence of external enforcement measures (Pruckner \& Sausgruber, 2006).

Justifications offer another way to solve ethical inconsistencies (Ayal \& Gino, 2011; Gino \& Ariely, 2012). People may justify their actions by reference to norms (“"everyone is doing it"), to external pressures ("if I do not do it, I'll be fired"), or to altruism and a greater cause ("this is what it takes to ensure people do not lose their jobs") (e.g., Gino \& Pierce, 2009; Sachdeva, Iliev, \& Medin, 2009; Kulik, Sledge, \& Mahler, 1986). Other factors attenuating perceived unethical behavior include lack of intent, lack of clear harm, or absence of a concrete victim (Ritov \& Baron, 1990; Gino, Shu, \& Bazerman, 2010; Spranca, Minsk, \& Baron, 1991).

Finally, adjustments of one's ethical standards might also occur. In fact, redefinitions, reinterpretations, and justifications allow one's own small deviations from ethical standards 
to go unnoticed and give way to gradual relaxation of one's ethical code and moral criteria (Bandura, 1999; Gino \& Bazerman, 2009; Tenbrunsel \& Messick, 2004).

Together, the factors these streams of research identify introduce ambiguity that blurs the criteria for judging what is right or wrong and thus lets people engage in dishonest behavior with little (if any) awareness of the violation of their ethics codes.

\section{Ethical Dissonance and Cognitive Dissonance}

Throughout the paper, we use the term ethical dissonance to refer to the inconsistency between one's unethical behavior and the need to maintain a moral self-image. ${ }^{1}$ Consistent with the definition of cognitive dissonance (see Festinger, 1957; Festinger \& Carlsmith, 1959), ethical dissonance is a psychological state in which an individual's cognitionsbeliefs, attitudes, and behaviors - are at odds. It is an aversive experience that motivates the person who experiences the inconsistency to resolve it and reduce the accompanying tension (Elliot \& Devine, 1994). Consistent with cognitive dissonance, ethical dissonance has strong motivational properties: (1) the dishonest act presents behavioral commitment (Brehm \& Cohen, 1962); (2) people are responsible for their dishonest acts (Wicklund \& Brehm, 1976); and (3) the dishonest act violates standards or expectations critical for the maintenance of a positive self-concept (Aronson, 1968).

We propose, however, that ethical dissonance should be singled as a unique case in the wide range of cognitive dissonance phenomena. The distinction we make is based on magnitude and centrality of the dissonance for self and society, and goes along the lines that identify racism and sexism as special cases of prejudice. First, consider the source of the dissonance. Current perspectives highlight several triggers for cognitive dissonance (Stone \& Cooper, 2001), including inconsistency between behavior and personal values/beliefs (e.g., Aronson, 1992; Aronson 1968; Thibodeau \& Aronson, 1992), threat to self-integrity (e.g. Steele, 1988; Spencer, Josephs \& Steele, 1993) and violation of societal norms (e.g., Cooper, 
1992; Cooper \& Fazio, 1984). Each of the three sources is sufficient to trigger cognitive dissonance. In ethical dissonance, all three sources apply: the behavioral misconduct presents a central inconsistency, threatens one's goodness, and is socially unacceptable. Second, consider the centrality of the dissonance. Ethics and behavioral definitions of right and wrong are central and consensual in society and are referred to as higher values and absolute rules rather than personal beliefs or agreed-upon norms (e.g. the 10 commandments; Aristotle, Nicomachean Ethics). Consequently, morality is central for both the private and the public self (Chaiken, Giner-Sorolla, \& Chen, 1996; Greenwald, 1980; Sanitioso, Kunda, \& Fong, 1990). Third, exposing ethical failure is associated with embarrassment, shame, or guilt and might further extend to tangible losses such as fines, forced resignation, and even time behind bars. Given the multiple sources, centrality for self and society and consequences of exposure, ethical dissonance poses a distinct threat to one's self-concept.

\section{Distancing Response to Ethical Dissonance}

Ambiguity has been a key characteristic in the wide variety of processes that help people rationalize their unethical behavior. In fact, ethical misconduct has to be somewhat ambiguous to allow misperceptions, reinterpretations, and justifications. In many cases, however, misconduct is undeniably wrong (e.g., falsely claiming to have an academic degree). When people cannot dismiss, reinterpret, or justify their own misconduct, we expect the threat to the self to be more intense. This intense ethical dissonance includes cognitive inconsistency, damage to self-integrity (e.g., shame and guilt), and fear of potential exposure and external sanctions. An effective way to resolve ethical dissonance should address these aspects, restore consistency, distance the self from the ethical flaw, and conceal the unethical behavior from the public eye.

We suggest that one central way to resolve ethical dissonance involves a distancing response that we call the pot calling the kettle black. Through this response, people judge the 
ethically questionable behavior of others more harshly and present themselves to others as virtuous and ultra-honest. Consequently, people dissociate their previous misconduct from the self and bury it as implausible. Going back to the opening example, MIT's dean of admissions tightened her criteria for judging others' unethical behavior, presented an ultrahonest attitude, and distanced herself from her own misconduct.

The proposed distancing response shares some similarities with another mechanism of cognitive dissonance reduction: bolstering. Early work on cognitive dissonance suggested that attitude might change in two directions due to cognitive dissonance. When the attitude is peripheral and isolated, adjusting it to the behavior will be the primary mode of dissonance reduction. If, however, the original attitude is strong and central, it will be bolstered by instances of consistent behavior that diminish the salience of the imbalance and allow the person to reestablish the validity of his/her initial set of central self-relevant beliefs (Abelson, 1959; Sherman \& Gorkin, 1980). For example, following the experience of dissonance between their feminist attitudes and performance implying sexism, participants tended to bolster their original attitude and express support in a feminist lawsuit. ${ }^{2}$

Although they share similar aspects, our proposed distancing mechanism differs from bolstering in a critical respect. According to attitude bolstering, following ethical misconduct, people who hold ethical values (e.g., honesty, fairness, kindness) as central indicators of their self-concept would behave more ethically in other situations. Such compensatory behaviors are consistent with existing research on moral regulation, indicating that a threat to the moral self leads people to emphasize their ethical characteristics, increase pro-social intentions, and cheat less (Jordan, Mullen, \& Murnighan, 2011; Sachdeva et al., 2009; Tetlock, Kristel, Elson, Green, \& Lerner, 2000). Compensatory behaviors also operate in the opposite direction, as is evident in moral licensing: a boost to the moral self leads people to relax their 
ethical standards and become more likely to cheat or behave immorally (Jordan et al., 2011; Khan \& Dhar, 2006; Monin \& Miller, 2001; Sachdeva et al., 2009).

Instead, the distancing response is oriented to the other rather than to the self, involves judging others more harshly rather than behaving more ethically and is based on impression management rather than on internal regulation of self-perception. Resolving ethical dissonance through a distancing response does not involve satisfying the desire to be moral, but rather the desire to appear moral by using strict ethical standards for moral judgment and self-presentation.

\section{Overview of the Studies}

We demonstrate the "pot calling the kettle black" phenomenon and examine the distancing response in six studies. In each study, we elicited ethical dissonance by asking participants to recall and write in private about a past undeniable unethical behavior they regretted. ${ }^{3}$ We compared the effects of experiencing ethical dissonance to various control conditions (e.g., ethically worthy conduct, neutral event, or negative event, as well as reports of unethical actions committed by others). We show that ethical dissonance poses a threat to the self-concept and influences how people judge the ethically questionable behaviors of others as well as the extent to which they present themselves as ultra-honest to others (Studies 1, 2 and 3). We also demonstrate that this double-distancing response is exclusive for ethical dissonance. It arises when participants recall their own ethical misconduct but not when they recall the misconduct of another person (Study 4), nor when they recall general personal failure or ethically-neutral dissonance (Study 5). Finally, we test a boundary condition of the distancing response to ethical dissonance and show the "pot calling the kettle black" phenomenon transpires when misconduct is undeniable and hidden, and dissolves when the misconduct can be justified and/or when its exposure is likely (Study 6). 


\section{Study 1: Stricter Criteria and Harsher Judgment}

In Study 1, we presented participants with a simplified hiring task in which a candidate's ethicality was clearly questionable, yet advantageous for the hiring firm. Participants evaluated the morality of the candidate and indicated their likelihood of hiring him. Preceding the hiring dilemma, we elicited ethical dissonance in one condition and compared its effects on our measures of interest to three different control conditions. We hypothesized that compared to the control conditions, ethical dissonance would result in harsher moral judgment of the candidate. In one of the control conditions, participants recalled a negative event from their past. We included this condition to rule out an alternative explanation of negative valence. We hypothesized that although the recollections of both unethical behavior and a negative event may lead to negative emotions, only the former, which poses a threat to the self, would result in ethical dissonance and thus lead to a distancing response.

\section{Method}

Participants. We recruited 141 undergraduates from local universities (76 female; $\left.M_{\text {age }}=21.68, S D=3.25\right)$ to participate in the study for a flat $\$ 7$ fee. We randomly assigned participants to one of four recall conditions: ethical dissonance, worthy conduct, neutral event, or negative event.

Procedure. Participants worked at computers in individual cubicles throughout the session. They first engaged in a writing task with our recall manipulation. Instructions varied according to the experimental condition. In the ethical-dissonance condition, participants recalled an unethical behavior from their past. The instructions read,

Please describe below one unethical thing you have done, one that made you feel guilt, regret or shame. Other people engaging in this type of introspective task frequently write about instances where they acted selfishly at the expense of someone else, took advantage of a situation and were dishonest, or an event in which they were untruthful or disloyal. 
In the worthy-conduct condition, the instructions read,

Please describe below one worthy thing you have done, something that made you feel really happy, pure or whole. Other people engaging in this type of introspective task frequently write about instances where they helped other people, acted unselfishly or honestly, participated in an exciting event, or did something that helped them connect with their true self.

In the neutral-event condition, the instructions read,

Please think of how you spend your evenings and describe below a typical instance. Other people engaging in this type of introspective task frequently write about instances where they make dinner, watch TV, read a book, or spend time with friends.

In the negative-event condition, the instructions read,

Please describe below a negative event that happened to you, one that made you feel disappointment, sadness, anxiousness, or embarrassment. Other people engaging in this type of introspective task frequently write about instances where a vacation was cancelled at the last moment, a sentimental object was lost or broken, someone close got seriously sick, or about a situation where they were embarrassed in front of family or friends.

Participants engaged in this task for a few minutes. The instructions were presented onscreen, and participants wrote a few paragraphs on a separate piece of paper, which, as we had informed them in the general instructions to the study, they shredded at the end of the study. Next, to capture the effect of the recall manipulation on self-image, participants completed a three-item state version of the self-esteem scale (Heatherton \& Polivy, 1991; see also Rosenberg, 1979). Specifically, they indicated how much they agreed with each of three statements on a 7-point scale (1=strongly disagree, 7=strongly agree): (1) Right now, I feel good about myself; (2) Right now, I like the way I look; and (3) Right now, I feel I am a person of worth.

As their second task, participants read the following hiring scenario:

Please imagine you work in the HR department of an advertisement company. You have been interviewing a candidate who appears to be qualified for the job. When the interview was finished, you still had a few minutes left and you asked the candidate what he can do for your company that someone else cannot. In response, the candidate implied that he managed to have access to some classified files of several companies in the field. 
Participants then judged the morality of the candidate by answering the following questions: (1) How likely would you be to hire this candidate for the job? (9-point scale: 1=not likely at all, 9=very likely); (2) How loyal to the company do you think this candidate would be? (9-point scale: 1=not loyal at all, 9=very loyal); (3) How honest do you think this candidate would be on the job? (9-point scale: $1=$ not honest at all, $9=$ very honest).

\section{$\underline{\text { Results and Discussion }}$}

Manipulation check. We averaged the self-esteem items to one aggregate score $(\alpha=.87)$. Participants' aggregate scores differed by condition, $F(3,137)=17.89, p<.001$, $\eta_{p}{ }^{2}=.28:$ they were lowest in the ethical-dissonance condition, intermediate in the neutral condition and the negative-event condition, and highest in the worthy-conduct condition (see Table 1). All paired comparisons were significant at the $1 \%$ level, except for the difference between the mean ratings of the neutral condition and the negative-event condition $(p=.77)$.

Likelihood of hiring. As predicted, participants were least likely to hire the candidate in the ethical-dissonance condition and more likely to hire the candidate in the control conditions. An ANOVA using our manipulation as the between-subjects factor revealed a significant effect for condition, $F(3,137)=12.13, p<.001, \eta_{p}{ }^{2}=.21$ (see Table 1 ). The likelihood of hiring reported in the ethical-dissonance condition differed significantly from that reported in the worthy-conduct condition, the neutral-event condition, and the negativeevent condition (all $p s<.001$ ). Hiring likelihoods across the three control conditions did not differ significantly (all $p \mathrm{~s}>.34)$.

Loyalty to company. As Table 1 shows, a similar analysis revealed perceived loyalty to the company also varied by condition, $F(3,137)=3.54, p<.02, \eta_{p}{ }^{2}=.07$. Participants in the ethical-dissonance condition were more suspicious of their candidate's future loyalty to the company than were participants in the worthy-conduct condition $(p<.01)$, the neutral-event 
condition $(p<.02)$, and the negative-event condition $(p<.01)$. The ratings in the three control conditions did not differ significantly (all $p \mathrm{~s}>.73$ ).

Honesty on the job. We found the same pattern of results when we examined participants' assessments of the candidate's honesty on the job, $F(3,137)=3.75, p<.02$, $\eta_{p}{ }^{2}=.08$. Expected honesty was ranked lowest in the ethical-dissonance condition and was higher in the worthy-conduct condition $(p<.02)$, the neutral-event condition $(p<.01)$ and the negative-event condition $(p<.01)$. Ratings on this measure did not differ significantly across the three control conditions (all $p \mathrm{~s}>.62$ ).

These results indicate that recalling past ethical misconduct posed a greater threat to the self and elicited harsher moral judgment of others. After recalling their own wrongdoing, participants were less likely to select the ethically questionable candidate for the job and judged him as less honest and less loyal to the firm.

As one may expect due to common norms and social desirability, judgments on all dependent variables were on the lower side of the scale across all experimental conditions. However, ethical dissonance resulted in the lowest judgments, whereas the three control conditions were indistinct. The similar responses elicited by the recall of worthy conduct, a neutral event on one hand, and a recall of a negative event on the other hand rule out the possibility that a general negative valence tightened decision criteria in the experimental condition, and distinct the distancing response to the experience of ethical dissonance.

\section{Study 2: Ultra-honest Self-presentation}

Going back to the opening example, the dean of admissions was a dominant presence at MIT, a leader in her profession, and a remarkable spokeswoman for easing the stress of college admissions. She served on numerous higher-education boards, including the National Association for College Admission Counseling's commission on standardized testing, and 
was scheduled to train college admissions staff from around the country to serve as the next generation of deans and leaders in the field.

One may consider these activities as evidence of moral cleansing. Studies have shown moral cleansing occurs through various behaviors, including moral statements, pro-social intentions, and actual moral behavior (Jordan et al., 2011; Sachdeva et al., 2009; Tetlock et al., 2000). In line with the general distinction between the private and public self (see Schlenker, 1980) and the specific distinction between internalization and symbolization aspects of moral identity (Aquino \& Reed, 2002), differentiating the motivation for moral cleansing from the motivation for moral self-presentation is useful.

We suggest that lecturing about ethical issues and outlining guidelines for appropriate behavior reflect self-presentation and regulation of the public self rather than moral cleansing and regulation of the private self. Building on Aquino and Reed (2001), we propose these actions symbolize morality, indicate the desire to manage virtuous impression, and may even affect the ethical conduct of other people. However, these actions are less likely to be correlated with actual change in ethical conduct. Accordingly, the main goal of Study 2 was to find evidence of the self-presentation aspect of the distancing response following ethical dissonance.

We tested moral-self presentation with a simplified task in which we asked participants to advise a friend facing an ethical dilemma between doing what was profitable and what was right. We chose this task for two reasons. First, providing advice simulates self-presentation as it occurred in the examples mentioned above of public speaking, training, and counseling. Second, instead of contemplating their own compensatory behaviors (i.e., moral cleansing), participants had to consider someone else's behavior. Studies on advice giving indicate that advice frequently promotes social norms and desirable long-term goals, whereas choice for the self is more sensitive to immediate temptation and feasible short-term 
goals (Danziger, Montal, \& Barkan, in press; Kray \& Gonzales, 1999). Advice on ethical matters would reasonably emphasize what is right, as that is the socially desirable option. However, we hypothesize that the experience of ethical dissonance and the tension it creates will polarize this tendency further to the point where advisers will not acknowledge the dilemma. We expected advisers experiencing ethical dissonance to present an ultra-honest self incapable of wrongdoing by overstressing the unethicality of the behavior in question, ignoring the temptation it posed, and providing overly righteous advice.

\section{Method}

Participants. We recruited 152 undergraduates from local universities (80 female; $M_{\text {age }}=22, S D=4.92$ ) to participate in the study for a flat $\$ 7$ fee. We randomly assigned participants to one of three recall conditions: unethical behavior, worthy conduct, or neutral event.

Procedure. We used the same recall task and the same instructions of Study 1. Upon completion of the writing task, participants completed the self-esteem scale used in Study 1 $(\alpha=.91)$.

Next, we asked participants to think of a good friend who encountered two ethical dilemmas. In the first dilemma, the friend participated in a job interview and happened to see a password that would reveal the questions included in the next day's interview. The friend called for advice, unsure whether to copy the password and use it to prepare for the interview. In the second dilemma, which we adapted slightly depending on the participant's gender, the friend was preparing for an important social event and was considering whether to return an expensive object (dress or watch) she/he had recently bought and used, and replace it with one more suitable for the event (see Appendix A for detailed scenarios).

For each dilemma, participants indicated (1) how wrong that behavior was (copy the password, exchange the dress/watch), (2) how likely they would be to engage in the described 
behavior had they been in the same situation, and (3) how likely they would be to encourage their friend to behave dishonestly. Participants answered these questions using a 9-point scale (1= not at all, 9=very much).

\section{$\underline{\text { Results and Discussion }}$}

Manipulation check. As shown in Table 2, participants' self-reported state self-esteem varied by condition, $F(2,146)=57.52, p<.001, \eta_{p}{ }^{2}=.44$. Participants scored lowest in the ethical-dissonance condition, intermediate in the neutral condition, and highest in the worthyconduct condition. All paired comparisons were significant at the $1 \%$ level.

Perceived unethicality of behaviors. A repeated-measure ANOVA using gender and our manipulation as the between-subjects factors and scenario as the within-subjects factor revealed a significant main effect for condition, $F(2,146)=5.82, p<.01, \eta_{p}{ }^{2}=.07$ (see Table 2). Participants who experienced ethical dissonance rated the questionable behaviors in the two scenarios as more unethical than did participants in the worthy-conduct condition $(t[149]=2.70, p<.01)$ and the neutral condition $(t[149]=3.10, p<.01)$. The worthy and neutral conditions did not differ significantly $(t[149]<1, p=.65)$. The effects of gender, gender-bycondition, and gender-by-scenario interactions were not significant ( $p s>.60)$.

Likelihood of self to behave unethically. Self-reported likelihood to behave unethically varied by condition, $F(2,146)=6.82, p=.001, \eta_{p}{ }^{2}=.09$. As expected, participants in the ethical-dissonance condition presented themselves as ultra honest and rated themselves as least likely to behave unethically in the two dilemmas, whereas participants in the worthyconduct condition and the neutral condition were more likely to admit they might have taken the unethical route had they been in their friend's shoes (see Table 2). The ethical-dissonance condition differed significantly from the worthy-conduct condition $(t[149]=2.96, p<.01)$ and the neutral-event condition $(t[149]=3.29, p<.01)$. Again, the worthy and neutral conditions 
did not differ significantly $(t[149]<1, p=.69)$. The effects of gender, gender-by-condition, and gender-by-scenario interactions were insignificant ( $p s>40)$.

Guiding others to behave ethically. Finally, a repeated-measure ANOVA using gender and our manipulation as the between-subjects factors and scenario as the within-subjects factor revealed a significant main effect for condition, $F(2,146)=9.74, p<.001, \eta_{p}{ }^{2}=.12$. As we predicted, participants in the ethical-dissonance condition provided overly righteous advice and were least likely to recommend the unethical behavior to their friends (see Table 2). Participants in the worthy-conduct condition $(t[149]=3.62, p<.001)$ and the neutral-event condition $(t[149]=3.77, p<.001)$ were more likely to realize the temptation in their recommendations. The worthy and neutral conditions did not differ significantly $(t[149]<1$, $p=.81)$. The main effects of gender and scenario and the gender-by-condition interaction were insignificant $(p s>.20)$.

Overall, these results indicate that experiencing ethical dissonance led participants to engage in impression management and present themselves as ultra-honest. When facing an ethical dilemma, people often have a strong sense of what's right and wrong. Social desirability concerns hinder advisers from openly admitting the temptation associated with unethical behavior. Yet the benefit of looking up a list of interview questions is obvious, as is the lure to exchange a barely used item for a preferable product. Balanced advice should at least acknowledge the difficulty of resisting such unethical temptations. Our findings suggest participants in the two control conditions recognized the difficult choice these dilemmas posed. Participants whose self-concept was threatened by ethical dissonance were unable to do so. Forced to face their own wrongdoings, these participants dismissed the dilemma, reported they would not be tempted to behave unethically, and provided overly righteous advice to their friend. 
Interestingly, as long as the ethical failure is not exposed, the distancing response may allow perpetrators to appear better than others, enjoy an honest reputation, and even serve as role models. Moreover, the ultra-honest attitudes they present, though false, may shape their immediate environment via the strict choices and policies they apply to guide the behavior of others around them. Elliot Spitzer, the former governor of New York (2007-8), provides a recent example. Prior to the exposure of the highly reputed and promising politician as Client 9 of a prostitution ring, Spitzer actively shaped public agenda and eagerly pursued organized crime, white-collar corruption, and prostitution.

\section{Study 3: Double Distancing: I Am Righteous, Others Are Evil}

The results of Studies1 and 2 demonstrate a double-distancing response to ethical dissonance. On the one hand, people shift their view of their surroundings to the negative end of the scale and see more evil in others. On the other hand, individuals shift their self-image to the positive end of the scale and present themselves as highly moral and more ethical than other people. Our findings may be limited, however, to situations in which decisions could have made participants accomplices in cheating (i.e., hiring a dishonest person or advising a friend to behave dishonestly). To solve this limitation and extend the demonstration of the distancing response, we next employed the Multi Aspect Scale of Cheating (MASC, developed by Barkan, 2008, and used in Gino, Norton, \& Ariely, 2010). In this general measure, people provide likelihood judgments of others' ethically questionable behaviors in various life domains.

Importantly, in Study 3, we tested whether the double-distancing process operates consciously or unconsciously. Past research on self-presentation differentiates between selfdeceptive enhancement and impression management (Paulhus, 1991a). Self-deceptive enhancement refers to the unconscious dimension of self-presentation and is defined as the tendency to see oneself in an overly favorable light and as possessing greater skills or 
aptitudes than reality can warrant. Impression management refers to the conscious dimension of self-presentation and reflects a deliberate, false response aimed at creating a favorable selfimage tailored to an audience (Crowne \& Marlowe, 1960; Paulhus, 1991b). It is a form of lying or "faking" (Furnham, Petrides, \& Spencer-Bowdage, 2001). Employing Paulhus's (1991a, 1991b) Balanced Inventory of Desirable Responding (BIDR) to measure selfdeceptive enhancement and impression management, Study 3 directly tested these competing interpretations of the ultra-honest self-presentation. ${ }^{4}$

\section{Method}

Participants. We recruited 68 undergraduates from local universities (38 male, $M_{\text {age }}=21.18, S D=2.33$ ) to participate in the study for a flat $\$ 5$ fee. We assigned participants randomly to one of two conditions: an ethical-dissonance or a worthy-conduct condition. (We employed only these two conditions since we found no differences across control conditions in Studies 1 and 2.)

Procedure. We used the same instructions and procedure for the recall task as in Studies 1 and 2. After the writing task, participants completed the state self-esteem scale as in Studies 1 and $2(\alpha=.86)$.

Next, participants completed the MASC (see Appendix B), which included three sets of questions (we randomized their order of presentation). The first set of questions included common instances of everyday misconduct and asked participants to think of people they knew and to state on a 7 -point scale ( $1=$ not likely, $7=$ very likely) how likely these people would be to engage in each of eight misconduct behaviors, such as "Inflate their business expense report." The second set of questions asked participants to read six common excuses such as "I thought I already sent that e-mail out. I am sure I did" and rate the likelihood they were lies (1=probably a lie, $7=$ probably true). Finally, in the third set of questions, participants read two ethical business dilemmas and evaluated on a 7-point scale ( $1=$ not 
likely, 7=very likely) the likelihood that the actor in each dilemma would choose the unethical option.

Finally, the third task presented participants with Paulhus's (1984) BIDR. Participants indicated the extent to which they agreed with each of 40 statements ( $1=$ strongly disagree, $7=$ strongly agree). The first 20 statements measured self-deceptive enhancement (e.g., "many people I meet are rather stupid," "I never regret my decisions;" $\alpha=.68$ ); the remaining 20 statements assessed impression management (e.g., "I never swear," "I don’t gossip about other people's business;" $\alpha=.87$ ).

$\underline{\text { Results and Discussion }}$

Manipulation check. Participants reported feeling worse about themselves in the ethical-dissonance condition $(M=4.67, S D=0.85)$ than in the worthy-conduct condition $(M=5.58, S D=0.96), t(66)=4.15, p<.001$.

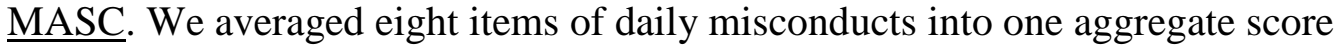
$(\alpha=.81)$. Participants in the ethical-dissonance condition rated other people as more likely to behave dishonestly $(M=5.15, S D=0.80)$ than did participants in the worthy-conduct condition $(M=4.64, S D=0.79), t(66)=2.64, p=.01$. We averaged the set of six common excuses to one aggregate score $(\alpha=.82)$. Participants in the ethical-dissonance condition interpreted common excuses as more likely to be a lie $(M=4.52, S D=0.91)$ than did participants in the worthyconduct condition $(M=3.96, S D=1.16), t(66)=2.22, p=.03$. Finally, and consistent with these results, participants in the ethical-dissonance condition judged the actors in the two ethical business dilemmas as more likely to behave dishonestly $(M=5.79, S D=1.06)$ than did participants in the worthy-conduct condition $(M=5.22, S D=1.32), F(1,66)=5.15, p<.03$, $\eta_{p}{ }^{2}=.07$.

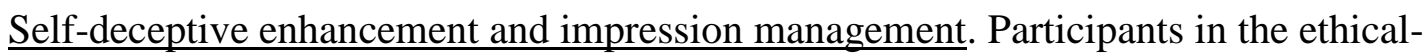
dissonance condition scored higher on impression management $(M=3.62, S D=0.89)$ than did 
participants in the worthy-conduct condition $(M=3.13, S D=0.76), t(66)=2.46, p<.02$. However, participants' ratings for self-deceptive enhancement did not differ significantly between conditions $(M=4.19, S D=0.66$ vs. $M=4.20, S D=0.43, p=.95) .^{5}$

These findings provide further evidence for the double-distancing mechanism triggered by ethical dissonance. Consistent with our previous results, recalling their own unethical behavior led participants to see more evil in others. Compared with people who recalled a worthy past deed, those experiencing ethical dissonance judged the unethical behavior of others more harshly. They also rated daily misconduct as more likely to occur, judged common excuses to be less truthful, and estimated that when facing an ethical dilemma, others would be more likely to behave dishonestly. The results of Study 3 also indicated that participants engaged in impression management rather than in unconscious self-deceptive enhancement. That is, the distancing response to experiencing ethical dissonance reflects a deliberate effort to present an ultra-honest and righteous self-image in a world that is portrayed as sinful.

\section{Study 4: Ethical Dissonance or Salience of Ethicality}

We suggested that the "pot calling the kettle black" phenomenon is rooted in the experience of ethical dissonance and the threat to one's own self-concept. One may argue, however, that our recall manipulation simply increased the salience of ethical standards. One problem with this argument is that salience of ethical considerations should increase whether recollections are of misconduct or of worthy behavior. Our findings indicate that the distancing response is triggered exclusively by recollections of ethical failures and not by recollections of ethical accomplishments. Still, failures may be more salient than accomplishments (Rozin \& Royzman, 2001), and thus saliency of (un)ethicality may explain the results of Studies 1-3. This alternative hypothesis posits that contemplating an incident of 
ethical misconduct would elicit the distancing response whether the behavior was committed by the self or by another person.

To rule out this alternative explanation, Study 4 compares three conditions in which we manipulated the perpetrator's identity. In one condition, we asked participants to recall their own past unethical behavior (self ethical-dissonance). In two control conditions, we asked participants to recall either an unethical action of a close friend or a family member (close other), or an unethical behavior carried by someone they did not know personally (distant other). Thus, instead of a simple comparison between self and other, we tried to capture a continuous dimension of social distance. If threat to the self played a key role, the experience of ethical dissonance should be most intense in the self condition and non-existent in the distant-other condition. However, recalling an unethical behavior of a close other (e.g., friend, partner) should be relevant to one's self-concept and elicit some tension. Accordingly, we expect the distancing response will be most pronounced in the self condition, lower in the close-other condition, and null in the distant-other condition.

Finally, we used Study 4 to test an interesting aspect of the distancing response suggesting that harsher moral judgment of others may be accompanied by inflated attribution error and a higher tendency to view others as inherently flawed. Utilizing the fundamental attribution error (FAE, for review, see Tetlock, 1985; Harvey, Town, \& Yarkin, 1981), we described cases in which people engaged in unethical behaviors, and asked participants to judge the extent to which the misconduct attested to the person's personality or reflected situational circumstances.

\section{Method}

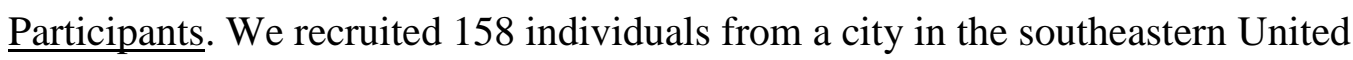
States (61 male; $\left.M_{\text {age }}=34.40, S D=13.08\right)$ to participate in the study for a flat $\$ 5$ fee. We 
randomly assigned participants to one of three recall conditions of ethical misconduct: self, close other, and distant other.

Procedure. For the self condition, we used the same instructions as in the recall task included in Studies 1-4. Instructions for the close [distant] other conditions read,

Please describe one unethical thing that someone close to you [someone you do not know in person] has done. You can think about a romantic partner, a family member or a really close friend. [You can think about someone you barely know like a friend of a friend, or a public figure you read about.]

Describe an unethical thing this person did to someone else and that to your knowledge made this person feel guilt, regret or shame. Make sure you describe something that did not hurt you and was not done at your expense. Other people engaging in this type of introspective task frequently write about instances where people who are close to them [they do not know] acted selfishly at the expense of someone else, took advantage of a situation and were dishonest, or an event in which these people were untruthful or disloyal.

Upon completion of the writing task, participants completed the three-item state selfesteem scale ( $\alpha=.87)$ and Paulhus's (1984) BIDR, assessing both self-deceptive enhancement $(\alpha=.76)$ and impression management $(\alpha=.90)$.

Next, participants read two vignettes (adapted from Study 2) describing ethical misconducts committed by a student from the same university. In one case, a student used a password he happened to see to prepare for a next-day interview. In a second case, a student returned an expensive dress/watch she/he had recently bought and used. For each vignette, we asked participants to answer the following questions using a 9-point scale ( $1=$ not at all, 9=very much): (1) To what extent is the described behavior wrong? (2) How honest is this student? (3) To what extent does this behavior attest to this student's personality? (4) To what extent is this behavior a circumstantial result of the specific situation? (5) How likely would you be to do the same under these circumstances? Questions 1and 2 focus on moral judgment of the other person, questions 3 and 4 assess the fundamental attribution error (FAE), and question 5 reflects self-presentation.

$\underline{\text { Results and Discussion }}$ 
Manipulation check. Self-esteem scores were lower in the self condition than in the close-other condition $(p<.01)$ and the distant-other condition $(p<.001), F(2,155)=8.76$, $p<.001, \eta_{p}{ }^{2}=.10$ (see Table 3). Contrary to our expectations, threat to the self did not correspond with social distance, and the difference between self-esteem scores in the closeother and distant-other conditions was not significant $(p=.11)$.

Self-deceptive enhancement and impression management. Participants in the self condition ranked higher on impression management than did participants in the close-other condition and the distant-other condition, $F(2,155)=3.88, p=.023, \eta_{p}{ }^{2}=.05$ (see Table 3 ). Contrary to the expected effect of social distance, the difference in impression management between close other and distant other was not significant ( $p=.43)$. Replicating Study 3, ratings for self-deceptive enhancement did not differ significantly across the three conditions, $p=.85$.

Judging behaviors harshly. For the remaining dependent measures, we first conducted repeated-measure ANOVAs using gender and our manipulation as the between-subjects factors and using scenario as the within-subjects factor. Across all dependent measures, the effects of gender, scenarios, and the gender-by-scenario interaction were not significant. We thus report results averaged across the two scenarios (see Table 3 for descriptive statistics across conditions). Participants rated the ethically questionable behaviors in the two scenarios differently across conditions, $F(2,155)=3.88, p=.023, \eta_{p}{ }^{2}=.05$. They rated questionable behaviors as more unethical in the self condition than in the close-other condition $(p<.05)$ and in the distant-other condition $(p<.01)$. Contrary to the expected effect of social distance, the close-other and distant-other conditions did not differ significantly ( $p=.37)$.

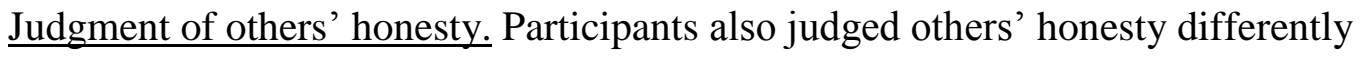
across conditions, $F(2,155)=5.58, p=.005, \eta_{p}{ }^{2}=.07$. In the self condition, they judged others most harshly and rated the wrongdoers across the two scenarios as least honest, whereas participants in the close-other condition $(p=.015)$ and the distant-other condition $(p=.001)$ 
were more forgiving and rated wrongdoers' honesty higher. Social distance did not affect the distancing response. Again, the close-other and distant-other conditions did not differ significantly $(p=.31)$.

Presenting self as ultra-honest. Participants' self-reported likelihood to behave unethically also varied by condition, $F(2,155)=5.62, p=.004, \eta_{p}{ }^{2}=.07$. In the self condition, participants presented an ultra-honest self and rated themselves as least likely to behave unethically in the two situations, whereas participants in the close-other condition $(p=.009)$ and the distant-other condition ( $p=.001)$ were more likely to admit they might have taken the unethical route had they been in the described situation. Social distance did not affect self presentation, and the close-other and distant-other conditions did not differ significantly $(p=.45)$.

Fundamental attribution error (FAE). To test whether the experience of ethical dissonance inflated the FAE, we analyzed the difference scores between participants' responses to question 3 (dispositional attribution) and question 4 (situational attribution). Positive scores indicate participants attributed higher weight to disposition, and negative scores indicate they attributed higher weight to the situation. A difference score of zero indicates equal weight to both factors (see Table 3). The difference scores assessing the FAE varied across conditions, $F(2,155)=4.74, p=.01, \eta_{p}{ }^{2}=.06$. Participants in the self condition assigned larger weight to wrongdoers' disposition than to situational circumstances $(M=1.27$, $S D=2.47)$, whereas participants in the close-other condition $(M=-.13, S D=2.43 ; p<.05)$ and the distant-other condition $(M=-.38, S D=3.13 ; p<.02)$ gave wrongdoers a slight benefit of the doubt and assigned more weight to situational circumstances. Note that the dispositional attribution in the self condition is larger by an order of magnitude compared to the situational attributions in the other conditions. Similar to the other dependent measures, social distance 
did not affect the fundamental attribution error, and the close-other and distant-other conditions did not differ significantly $(p=.61)$.

Consistent with the ethical dissonance hypothesis, the "pot calling the kettle black" phenomenon appeared in the self condition but not in the other conditions. The findings rule out the alternative explanation of ethical saliency, indicating that threat to the self is critical for the distancing response. Recalling their own ethical misconduct led participants to engage in deliberate impression management, to judge questionable behaviors and perpetrators more harshly, and to present themselves as unlikely to engage in unethical behavior. Interestingly, ethical dissonance inflated the fundamental attribution error, indicating the distancing response extends beyond the single incident, leading participants to discount situational circumstances and stress others' flawed personalities.

However, contrary to our expectation, the threat to the self and the distancing response did not correspond with social distance. Recalling ethical misconduct of a close other did not threaten participants' self-concept, and their responses in this condition were indistinct from responses in the distant-other condition. One explanation is that the effect is unique to the self and is dichotomous rather than continuous in nature. Another possibility is that our manipulation did not highlight the relevance of the behavior of close others to participants' self-concept. Thus, the effect of social distance remains uncertain and requires further investigation.

\section{Study 5: Ethical Dissonance, Personal Failure, or Cognitive Dissonance}

To further support the ethical dissonance hypothesis, Study 5 tested two more alternative explanations to the distancing response. The first explanation accepts the key role of threat to the self but challenges its specificity. Threats to the self may or may not involve an experience of dissonance, and may or may not involve ethical issues. Accordingly, a personal-failure hypothesis suggests the distancing response can be triggered by ethically- 
neutral threats to the self-concept (e.g., flunking an important test, losing a job to a better candidate, lying to a loved one). A second explanation accepts the critical role of the experience of dissonance yet questions the claim that the dissonance has to be ethical in nature. Alternatively, a cognitive-dissonance hypothesis suggests the distancing response can be triggered by the experience of ethically-neutral dissonance. Note that both alternative explanations partially concur with the underlying mechanism of the distancing response, yet each of them offers a different generalization. To test these alternative explanations, Study 5 compares three conditions of ethical dissonance, ethically-neutral threats to the self, and ethically-neutral cognitive dissonance.

As in our previous studies, we measure threat to the self with the state self-esteem measure. We assume each of the three conditions threatens one's self-concept, and we do not expect to find differences in the general state self-esteem measure. We measure the distancing response with MASC, and impression management with Paulhus's (1984) BIDR. If the distancing response we demonstrated in previous studies is specific to ethical dissonance, we should observe it when participants recall personal ethical failure, but not when they recall personal failure or cognitive dissonance that are ethically-neutral.

\section{Method}

$\underline{\text { Participants. }}$ We recruited 156 individuals from a city in the southeastern United States (67 male; $M_{a g e}=30.79, S D=8.84$ ) to participate in the study for a flat $\$ 5$ fee. We assigned participants randomly to one of three conditions: ethical dissonance, personal failure, or cognitive dissonance.

Procedure. We followed the same procedure as in our previous studies. For the ethical-dissonance condition, we used the same instructions as in Studies 1-4. In the ethically neutral personal-failure condition, the instructions read,

Please describe below a personal failure. Describe something in which you failed. Something that made you feel insecure, vulnerable and unsuccessful. Other people 
engaging in this type of introspective task frequently write about instances where they failed to keep a diet, flunked an important test, were not accepted to the school they applied to, or lost a job to a better candidate.

In the ethically neutral cognitive-dissonance condition, the instructions read,

Please describe an instance in which you behaved in a way that contradicted an attitude or a value that is important to you. Describe a behavior that made you feel you betrayed your own principles and beliefs. Other people engaging in this type of introspective task frequently write about instances where they believe in Green but drive to campus by their own car rather than using the free public transportation or hate the policy of Microsoft but keep using their software because they do not have the energy to learn new software. In other instances people admit that though they should be informed about serious world problems they usually read the sports or gossip sections.

Upon completion of the writing task, participants completed the state self-esteem measure $(\alpha=.80)$. Next, they completed the MASC questionnaire as in Study 3 (see Appendix B), followed by Paulhus's (1984) BIDR assessing impression management ( $\alpha=.87)$ and selfdeceptive enhancement $(\alpha=.77)$.

$\underline{\text { Results and Discussion }}$

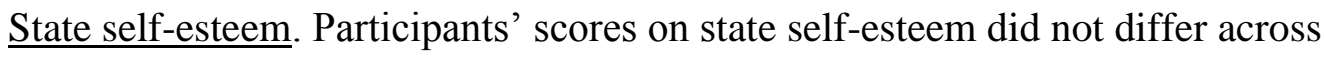
conditions $(p=.41)$, suggesting the experimental conditions resulted in comparable levels of threat to the self (see Table 4 for all descriptive statistics).

$\underline{\text { MASC. }}$. We first examined whether the aggregate measure of daily misconduct $(\alpha=.83)$ varied by condition $F(2,153)=12.08, p<.001, \eta_{p}{ }^{2}=.14$. Participants in the ethicaldissonance condition rated other people as more likely to behave dishonestly than did participants in the personal-failure condition and in the cognitive-dissonance condition ( $p<.001$ for both comparisons). The difference between the latter two conditions was not significant $(p=.94)$.

We averaged the set of six common excuses to one aggregate score $(\alpha=.66)$ and verified it varied by condition $F(2,153)=4.68, p=.011, \eta_{p}{ }^{2}=.06$. Participants in the ethicaldissonance condition interpreted common excuses as more likely to be a lie than did 
participants in the other two conditions ( $p<.02$ for both comparisons). The difference between the two other-unethical-deed conditions was not significant $(p=.61)$.

Finally, participants in the ethical-dissonance condition judged the actors in the two ethical business dilemmas as more likely to behave dishonestly than did participants in the other two conditions ( $p<.01$ for both comparisons), $F(2,153)=12.68, p<.001, \eta_{p}{ }^{2}=.14$. The difference on this rating between the latter two conditions was not significant $(p=.21)$.

Self-deceptive enhancement and impression management. Participants' impression management score differed significantly across conditions $F(2,153)=2.88, p=.059, \eta_{p}{ }^{2}=.05$. Participants in the ethical-dissonance condition ranked higher on impression management than did participants in the other two conditions ( $p<.05$ for both comparisons). The difference between these two latter conditions was not significant $(p=.91)$. Participants' ratings for selfdeceptive enhancement did not differ significantly across conditions, $p=.51$.

These results support the specificity of the ethical-dissonance hypothesis, indicating that the distancing response was elicited by a specific threat to the self, resulting from behavioral violations of one's own ethical values. Ethically neutral threats to the self as well as ethically neutral cognitive dissonance did not trigger the distancing response.

\section{Study 6: Boundary Conditions of the Contrast Response}

Our final study tested two boundary conditions of the distancing response. A first boundary condition concerns justifiability. Earlier, we suggested distancing arises when the ethical misconduct is undeniable and people cannot dismiss, reinterpret, or justify their wrongdoing. Although the distancing response dissociates people from their wrongdoing, it cannot make the misconduct or the experience of ethical dissonance "go away." In that respect, it is inferior to other solutions that blind people to their unethical behavior. Accordingly, we expected to observe the distancing response when people could not deny 
their ethical misconduct, but that the response would dissolve when a (better) justification solution was viable.

A second boundary condition concerns visibility. People tend to commit ethical misconducts in private, and exposure carries costs ranging from embarrassment, shame, and guilt to social sanctions. The distancing response protects people from potential exposure, presenting an ultra-honest self that is incapable of wrongdoing. If the misconduct is exposed, however, then false self-presentation is not only ineffective but actually harmful, as it adds sin to a crime. Accordingly, we hypothesized that we would observe the distancing response when people were certain their secret misconduct was safe, but that the response would dissolve when they realized exposure was highly likely.

To test these boundary conditions, we again asked participants to recall a personal unethical behavior they regretted. However, we manipulated the justifiability and the visibility of the recalled behavior. We measure the distancing response with two subsets of the MASC questionnaire (reflecting moral judgment of others) and with an ethical-dilemma advisory task (reflecting self-presentation).

\section{Method}

Participants. We recruited 128 undergraduates from local universities (75 female; $M_{a g e}=21.02, S D=2.95$ ) to participate in the study for a flat $\$ 7$ fee. We assigned participants randomly to one of four ethical misconduct conditions in a 2 (Justifiability: justifiable or undeniably wrong) X 2 (Visibility: visible or hidden) between-subjects design.

Procedure. As their first task, all participants recalled an unethical behavior they had committed in the past and wrote about it for a few minutes. In the hidden condition, participants wrote their description on a piece of paper, knowing they would shred it at the end of the experiment (as in all previous studies). In the visible condition, participants wrote their description on a piece of paper, knowing they would have to hand the folded paper to 
the experimenter upon completion of the writing task and before they continued with the next task (at the end of the experiment, we returned unopened written reports to the participants, who then shredded them). The justification manipulation varied the type of instructions participants received for the recall task. In the undeniably wrong condition, the instructions were identical to those employed in the standard ethical-dissonance condition in Studies 1-5. However, in the justifiable condition, we complemented the same instructions with additional sentences suggesting participants might be able to explain and justify their misconduct (additions appear here in italics to aid comparison). The instructions read as follows:

Please describe below one unethical thing that you have done that made you feel guilt, regret or shame. The instance you choose may have an explanation or justification. Other people engaging in this type of introspective task frequently write about instances where they acted selfishly at the expense of someone else, took advantage of a situation and were dishonest, or an event in which they were untruthful or disloyal. Other people's explanations and justifications frequently refer to the specific circumstances as well as to the intentions or actions of other people involved in the situation. Please accompany the description of the unethical action you have done with your explanation.

As a manipulation check, participants completed the state self-esteem scale $(\alpha=.80)$.

Next, they completed two subsets of the MASC questionnaire (daily misconducts and common excuses, see Appendix B) and an advisory task in which a friend contemplates using a password he found to prepare for a job interview (see Scenario 1 in Appendix A).

$\underline{\text { Results and Discussion }}$

Manipulation check. A 2 (Justifiability: justifiable or undeniably wrong) X 2 (Visibility: visible or hidden) between-subjects ANOVA using participants' ratings on the state self-esteem measure revealed a significant main effect for justifiability $F(1,124)=12.08$, $p^{<.01,}, \eta_{p}{ }^{2}=.09$. The effect of visibility was also significant, $F(1,124)=5.44, p<.03, \eta_{p}{ }^{2}=.04$. A significant interaction qualified these effects, $F(1,124)=8.24, p<.01, \eta_{p}{ }^{2}=.06$. As Table 5 shows, participants' self-esteem scores were lowest in our standard ethical-dissonance condition (i.e., undeniably wrong and hidden misconduct). Self-esteem scores in the other 
three conditions were higher ( $p<.001$ for all comparisons) and not significantly different from one another (all $p$ s for these comparisons were $>.41){ }^{6}$

MASC. The eight items of daily misconduct behaviors were averaged into one aggregate score $(\alpha=.82)$. A 2 (Justifiability) X 2 (Visibility) between-subjects ANOVA using this aggregate score as the dependent variable revealed a significant effect for justifiability, $F(1,124)=3.96, p<.05, \eta_{p}{ }^{2}=.03$, and a significant effect of visibility, $F(1,124)=12.25, p<.01$, $\eta_{p}{ }^{2}=.09$. A significant interaction qualified these effects, $F(1,124)=7.26, p<.01, \eta_{p}{ }^{2}=.06$ (see Table 5). Participants estimated the likelihood of daily misconduct highest in the undeniably wrong hidden condition. Likelihood estimations in the other three conditions were lower $(p<.001$ for all comparisons) and not significantly different from one another (all $p$ s for these comparisons were >.18).

A similar pattern of results emerged when participants judged the likelihood of common excuses being lies (we averaged the six items into one aggregate score, $\alpha=.65$ ). A 2 X 2 between-subjects ANOVA revealed a significant main effect for justifiability, $F(1,124)=4.43, p<.04, \eta_{p}{ }^{2}=.03$, and a significant effect of visibility, $F(1,124)=16.05, p<.001$, $\eta_{p}{ }^{2}=.12$. A significant interaction qualified these effects, $F(1,124)=13.54, p<.001, \eta_{p}{ }^{2}=.10$. Participants reported common excuses as more likely to be lies in the undeniably wrong hidden condition than in the other three conditions ( $p<.01$ for all comparisons). Ratings were not significantly different across the other three conditions (all $p$ s were >.28).

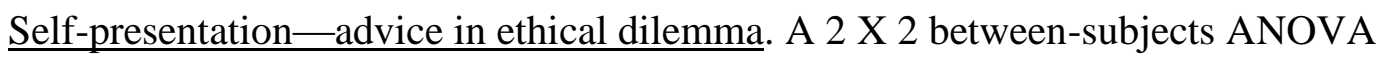
revealed a significant main effect for justifiability, $F(1,124)=7.32, p=.008, \eta_{p}{ }^{2}=.056$, and a non-significant effect of visibility, $F(1,124)<1, p=.51, \eta_{p}{ }^{2}=.003$. A significant interaction qualified these effects, $F(1,124)=5.49, p=.021, \eta_{p}{ }^{2}=.042$. Similar to our previous findings, participants in the undeniably wrong hidden condition presented an ultra-honest self and were 
the least likely of all four conditions to advise their friends to behave dishonestly. ( $p<.04$ for all comparisons).

Self-presentation-likelihood of self to behave unethically. A 2 X 2 ANOVA revealed a significant main effect for justifiability, $F(1,124)=13.61, p<.001, \eta_{p}{ }^{2}=.10$, and a non-significant effect for visibility, $F(1,124)<1, p=.37, \eta_{p}{ }^{2}=.006$. A significant interaction qualified these effects, $F(1,124)=5.99, p=.016, \eta_{p}{ }^{2}=.046$. Participants in the undeniably wrong hidden condition also rated themselves as least likely to behave dishonestly had they been in the same situation ( $p<.03$ for all comparisons). On both questions, differences across the other three conditions were not significant.

The findings indicate the distancing response appeared when the ethical misconduct was both undeniable and hidden. Once the wrongdoing was visible and/or once participants could in some way justify it, participants abandoned the distancing solution.

\section{General Discussion}

In this paper, we used the term ethical dissonance to describe the experience triggered by a disparity between people's unethical behavior and the values associated with their moral self-image. Mild cases of ethical dissonance are solved by a variety of strategies that bound people's ethicality and allow them to be generally unaware of their misconduct, dismiss or justify their behavior, and gradually relax their ethical criteria. Our research focused on a stronger case of ethical dissonance, where people cannot deny their misconduct. We argued that the intense experience of ethical dissonance gives rise to a distancing response reflected in the "pot calling the kettle black" phenomenon. To dissociate themselves from their own misconduct people, judge the behavior of others more harshly and present themselves as more virtuous and ethical.

Studies 1-3 demonstrated that the "pot calling the kettle black" phenomenon. Inspired by a real-life example, Study 1 employed an admissions task. The findings indicated that 
recalling ethical misconduct posed a threat to the self and led to tightened ethical criteria and a higher likelihood of rejecting an ethically questionable candidate. In Study 2, recalling past misconduct led participants to present an ultra-honest self that is incapable of wrongdoing, and to provide over-righteous advice to others. Study 3 provided more evidence for the double-distancing mechanism. Importantly, the results of the third study demonstrated that presenting a better self-image as a result of experiencing ethical dissonance reflects conscious effort of impression management rather than unconscious bias of self-deceptive enhancement.

We designed Studies 4 and 5 to rule out alternative explanations for the doubledistancing mechanism resulting from experiencing ethical dissonance. Study 4 demonstrated that distancing arises exclusively when participants recall their own ethical misconduct but not when they recall the misconduct of another person, ruling out the alternative explanation of ethical salience. Contrary to our expectations, recalling a misconduct of close and distant other produced similar responses. More research is needed to determine whether the distancing response is unique to the self and dichotomous in nature, or whether it varies continuously with the intensity of the threat social distance creates. Interestingly, Study 4 extended the demonstration of the distancing response, indicating it involves a stronger tendency to attribute unethical behavior to flawed personality and to discount extenuating circumstances. Further support for the exclusiveness of the phenomenon was indicated in Study 5, in which a distancing response followed ethical dissonance but was not observed for ethically neutral threats to the self or ethically neutral cognitive dissonance.

Finally, Study 6 tested the boundary conditions of the distancing response, indicating the response transpires for undeniable and hidden misconduct, and dissolves if justification is viable and/or if exposure is likely.

\section{Theoretical Contributions}


Our research contributes to existing research in moral psychology and ethical decision making in several ways. First, it complements existing work on moral cleansing and licensing behaviors and extends the scope of moral-self regulation. Moral cleansing and licensing are commonly described as intra processes that are independent of an "other." Similar to the homeostasis mechanism, downward and upward deviations from a comfortable moral baseline lead people to add or subtract moral points and keep a dynamic balance of the inner self-concept (Jordan et al., 2011; Sachdeva et al., 2009). The double-distancing mechanism we demonstrated in this paper is a complementing process that operates at anter level where a moral self is negotiated against a lacking "other." Unlike moral cleansing and licensing behaviors that are oriented inward, distancing is oriented outward and aims for audience recognition.

Consistent with our theorizing, Wicklund and Gollwitzer (1981) list social reality as a critical element of self-completion, suggesting a "sense of progress toward a self-defining goal is dependent on the acknowledgment of others" (p. 93). Importantly, the two researchers also argue that self-symbolizing originates from an internal experience of incompleteness. The intertwining of internal experience and recognition by others is consistent with the interrelations between the private and the public self (Schlenker, 1980), the ideal and ought selves (Higgins, 1987).

Specific to moral behavior, the complementing set of the private regulation mechanism of cleansing/licensing and the public regulation mechanism of distancing corresponds with Aquino and Reed's (2002) differentiation between internalization and symbolization dimensions of moral identity. Converging with our findings, symbolization is correlated with impression management and with self-reports of pro-social behavior, whereas internalization is correlated with moral reasoning and actual pro-social behavior. 
Our research differs from work on moral hypocrisy (e.g., Batson, Kobrynowicz, Dinnerstein, Kampf \& Wilson, 1997), namely people's tendency to judge their own transgressions leniently while condemning others for the same behaviors. Generally, people are unaware of the double standards (lenient code for self vs. strict code for other) and maintain strong beliefs in their own morality. Alternatively, people find ways to redefine or rationalize their behavior and maintain their positive self-image. According to our theorizing, moral hypocrisy reflects mild cases of ethical dissonance. Distancing differs from moral hypocrisy in three respects. First, distancing is elicited when solutions of moral hypocrisy such as rationalizations and justifications fail. Second, distancing refers to self-presentation rather than to judgment of the self. Third, in the distancing response a person uses the same — overcompensating — ethical code for judgment of others and for self-presentation.

Related to this point, Shu, Gino, and Bazerman (2011) found that following unethical behavior, people morally disengaged and were more lenient toward cheating. Such leniency resulted from participants' justifying their own misbehavior as morally appropriate. In our research, participants could not rationalize their ethical misconduct. Thus, instead of showing lenience toward cheating (causing further threat to the self), they had to solve the internal tension with a distancing response and demonstrate stricter (rather than relaxed) criteria.

\section{$\underline{\text { Conclusion }}$}

Inconsistency between one's own unethical behavior and moral code elicits ethical dissonance, threatens the self-concept, and must be solved in a way that protects and recovers the self. Common solutions include reinterpretations and justifications of the behavior as well as gradual relaxation of moral criteria. Our work identifies a different mechanism to resolve ethical dissonance. When a certain behavior is undeniably wrong and people have little room to reinterpret their ethical misconduct, they distance themselves from their wrongdoing. 
Using an overcompensating ethical code, they judge others more harshly and present themselves as more virtuous and ethical.

Ethical behavior and moral judgment are commonly discussed as if they were interchangeable, despite the likelihood that they are not. Our work provides one example in which intentional disparity between the two allows people to benefit from their own dishonest behavior without compromising their moral ledger. 


\section{Appendix A: Scenarios used in Study 2}

\section{Scenario 1}

Imagine that one of your friends just called you to ask for your opinion. Your friend has an important interview tomorrow, which will determine whether or not he will be able to get a really good job as an analyst. Your friend is suitable for the job but he is worried about the interview being demanding. He is the type of person who does not perform at his best under stress. The questions for the interview will be chosen at random from a list that is kept in an online document which is password protected. Your friend was the last person to leave the room after an introductory luncheon for all the job candidates. As he was about to leave, he noticed that a company representative had left a folder on the table with information about tomorrow's interview. This is why your friend called you. He has the opportunity to write down the password and use it to prepare for the interview. Nobody would ever find out about this. He really needs your advice.

\section{Scenario 2 (for female participants)}

Imagine that one of your friends just called for advice. She has a date in a couple of days with someone she has been interested in for a long time. You've heard her talk about this person many times. In fact, you've seen her turn down a few offers just because she's so infatuated with this person. A mutual acquaintance finally helped, and the exciting date entails going to the opera, followed by dinner at a fancy restaurant. Your friend says she needs the date to go well. She feels she has just one chance and needs everything to be perfect. She has one expensive dress that she bought a couple of weeks ago for her cousin's wedding, but she doesn't think it is right for this date. Buying another dress is out of the question. She still has the receipt, and given that she only used the dress once, she is thinking about returning the dress and exchanging it for a more appropriate one for her dream date. Nobody would ever find out that she had actually worn the dress. She really needs your advice.

\section{Scenario 3 (for male participants)}

Imagine that one of your friends just called for advice. A few months ago he joined a law firm, and in a couple of days his colleagues and his boss are coming over to his house to have dinner and watch a football game. He's been talking about having the guys over since he joined the firm and finally everybody agreed on a date. Your friend is an excellent chef, and the plasma screen should do the trick for watching the game. However, your friend is stressed and says success is crucial. He feels he has just one chance at being accepted by his colleagues and needs everything to be perfect. His colleagues always wear the right suits and expensive watches. He does have an expensive watch he bought a couple of weeks ago, but he thinks it is not good enough to convey the right message. Buying another watch is out of the question. He still has the receipt, and given that he only used the watch once or twice, he is thinking about returning the watch and exchanging it for a more appropriate one. Nobody would ever find out that he actually used the watch. He really needs your advice. 


\section{Appendix B: MASC items used in Study3}

\section{Questions}

A. Please think of people you know and state how likely they are to engage in the following behaviors.

- Be in the express line with too many groceries.

- Board a plane before their group number is called.

- Inflate their business expense report.

- Tell their supervisor that progress has been made on a project, when none has been made at all.

- Take home office supplies from work.

- Lie to an insurance company about the value of goods that were damaged.

- Buy a garment, wear it and return it.

- Lie to their partner about the number of sex partners they had in the past.

B. Please read the following sentences and evaluate the likelihood that each of them is a lie.

- Sorry I'm late, traffic was terrible.

- My GPA is 4.0.

- It was good meeting you. Let's have lunch sometime.

- Sure, I'll start working on that tonight.

- Yes, John was with me last night.

- I thought I already sent that email out. I am sure I did.

\section{Scenarios}

1. Steve is the Operations manager of a firm that produces pesticides and fertilizers for lawns and gardens. A certain toxic chemical is going to be banned in a year, and for this reason is extremely cheap now. If Steve buys this chemical, produces and distributes his product fast enough, he will be able to make a very nice profit. Please evaluate the likelihood that Steve will use this chemical while it is still legal.

2. Dale is the Operations manager of a firm that produces health food. Their organic fruit beverage has 109 calories per serving. Dale knows people are sensitive to crossing the critical threshold of one hundred calories. He could decrease the serving size by $10 \%$. The label will say each serving has 98 calories, and the fine print will say each bottle contains 2.2 servings. Please evaluate the likelihood that Dale will cut the serving size to avoid crossing the 100 threshold. 


\section{References}

Abelson, R. P. (1959). Modes of resolution of brief dilemmas. Journal of Conflict Resolution, $3,343-52$.

Adler, A. (1930). Individual psychology. Oxford, England: Clark University Press.

Allport, G. W. (1955). Becoming. Basic considerations for a psychology of personality. New Haven: Yale University Press.

Aquino, K., \& Reed, A. II. (2002). The self-importance of moral identity. Journal of Personality and Social Psychology, 83, 1423-1440.

Aronson, E. (1968). Dissonance theory: Progress and problems. In Ableson et al. (Eds.), Theories of cognitive consistency: A sourcebook (pp. 5-27). Chicago: Rand McNally.

Aronson, E. (1992). The return of the repressed: Dissonance theory makes a comeback. Psychological Inquiry, 3(4), 303-311.

Ayal, S., \& Gino, F. (2011). Honest rationales for dishonest behavior. In M. Mikulincer \& P. R. Shaver (Eds.), The Social Psychology of Morality: Exploring the Causes of Good and Evil. Washington, DC: American Psychological Association.

Banaji, M. R., Bazerman, M. H., \& Chugh, D. (2003). How (un)ethical are you? Harvard Business Review, 81(12), 56-64.

Bandura, A. (1999). Moral disengagement in the perpetuation of humanities. Personality and Social Psychology Review, 3, 193-209.

Barkan, R. (2008). Measuring cheating with a multi-method scale. Unpublished manuscript.

Batson, C. D., Kobrynowicz, D., Dinnerstein, J. L., Kampf, H. C., \& Wilson, A. D. (1997). In a very different voice: Unmasking moral hypocrisy. Journal of Personality and Social Psychology, 72(6), 1335-1348. 
Baumeister, R. F., \& Newman, L. S. (1994). Self-regulation of cognitive inference and decision processes. Personality and Social Psychology Bulletin, 20, 3-19.

Brehm, J.W., \& Cohen, A.R. (1962). Explorations in cognitive dissonance. New-York: Wiley.

Chaiken, S., Giner-Sorolla, R., \& Chen, S. (1996). Beyond accuracy: Defense and impression motives in heuristic and systematic information processing. In P. M. Gollwitzer \& J. A. Bargh (Eds.), The psychology of action: Linking cognition and motivation to behavior (pp. 553-578).New York: Guilford Press.

Chatzidakis, A., Hibbert, S., Mittusis, D., \& Smith, A. (2004).Virtue in Consumption? Journal of Marketing Management, 20, 527-544.

Chugh, D., Bazerman, M. H., \& Banaji, M. R. (2005). Bounded ethicality as a psychological barrier to recognizing conflicts of interest. In D. A. Moore, D. M. Cain, G. F. Loewenstein, \& M. H. Bazerman (Eds.), Conflicts of interest: Problems and solutions from law, medicine and organizational Settings. London: Cambridge University Press.

Cooper, J. (1992). Dissonance and the return of the self-concept. Psychological Inquiry, 3(4), 320-323.

Cooper, J., \& Fazio, R. H. (1984). A new look at dissonance theory. In L. Berkowitz (Ed.), Advances in Experimental Social Psychology (pp. 229-262). Hillsdale, NJ: Erlbaum.

Crowne, D. P., \& Marlowe, D. (1960). A new scale of social desirability independent of psychopathology. Journal of Consulting Psychology, 24, 349-354.

Danziger, S., Montal, R., \& Barkan, R. (in press). Idealistic advice and pragmatic choice: A psychological distance account. Journal of Personality and Social Psychology.

DePaulo, B. M., Kashy, D. A., Kirkendol, S. E., Wyer, M. M., \& Epstein, J. A. (1996). Lying in everyday life. Journal of Personality and Social Psychology, 70(5), 979-995. 
Elliot, A.J., \& Devine, P.G. (1994). On the motivational nature of cognitive dissonance: Dissonance as psychological discomfort. Journal of Personality and Social Psychology, 67, 382-394.

Festinger, L. (1957). A theory of cognitive dissonance. Stanford, CA: Stanford University Press.

Festinger, L., \& Carlsmith, J. M. (1959). Cognitive consequences of forced compliance. Journal of Abnormal and Social Psychology, 58, 203-211.

Fischbacher, U., \& Heusi, F (2008). Lies in disguise. An experimental study on cheating. Thurgau Institute of Economics, Research Paper Series, 40.

Furnham, A., Petrides, K.V., \& Spencer-Bowdage, S. (2001). The effects of different types of social desirability on the identification of repressors. Personality and Individual Differences, 33, 119-330.

Gino, F., \& Ariely, D. (2012). The dark side of creativity: original thinkers can be more dishonest. Journal of Personality and Social Psychology.

Gino, F., Ayal, S., \& Ariely, D. (2009). Contagion and differentiation in unethical behavior: The effect of one bad apple on the barrel. Psychological Science, 20(3), 393-398.

Gino, F., \& Bazerman, M. H. (2009).When misconduct goes unnoticed: The acceptability of gradual erosion in others' unethical behavior. Journal of Experimental Social Psychology, 45(4), 708-719.

Gino, F., Norton, M., \& Ariely, D. (2010). The counterfeit self: The deceptive costs of faking it. Psychological Science, 21(5), 712-720.

Gino, F., \& Pierce, L. (2009). Dishonesty in the name of equity. Psychological Science, 20(9), 1153-1160.

Gino, F., Shu, L. L., \& Bazerman, M. H. (2010). Nameless + Harmless = Blameless: When seemingly irrelevant factors influence judgment of (un)ethical 
behavior. Organizational Behavior and Human Decision Processes, 111(2), 102-115.

Greenwald, A. G. (1980). The totalitarian ego: Fabrication and revision of personal history. American Psychologist, 35, 603-618.

Harvey, J. H., Town, J. P., \& Yarkin, K. L. (1981). How fundamental is "the fundamental attribution error"? Journal of Personality and Social Psychology, 43, 345-346..

Heatherton, T.F., \& Polivy, J. (1991). Development and validation of a scale for measuring state self-esteem. Journal of Personality and Social Psychology, 60, 895-910.

Higgins, E. T. (1997). Beyond pleasure and pain. American Psychologist, 52, 1280-1300.

Jones, S. C. (1973). Self and interpersonal evaluations: Esteem theories versus consistency theories. Psychological Bulletin, 79, 185-199.

Jordan, J., Mullen, E., \& Murnighan, J. K. (2011). Striving for the moral self: The effects of recalling past moral actions on future moral behavior. Personality and Social Psychology Bulletin, 37, 701-713.

Khan, U., \& Dhar, R. (2006). Licensing effect in consumer choice. Journal of Marketing Research, 43(May), 259-266.

Kray, L., \& Gonzales, R. (1999). Differential weighting in choice versus advice: I'll do this, you do that. Journal of Behavioral Decision Making, 12, 207-217.

Kulik, J. A., Sledge, P., \& Mahler, H. I. M. (1986). Self-confirmatory attribution, egocentrism, and the perpetration of self beliefs. Journal of Personality and Social Psychology, 50, 587-594.

Kunda, Z. (1990). The case for motivated reasoning. Psychological Bulletin, 108(3), 480-498

Lydon, J., Zanna, M.P., \&Ross, M. (1988). Bolstering attitudes by autobiographical recall: Attitude persistence and selective memory. Personality and Social Psychology Bulletin, 14, 78-86.

Mazar, N., Amir, O., \& Ariely, D. (2008). The dishonesty of honest people: A theory of self- 
concept maintenance. Journal of Marketing Research, 45(6), 633-644.

Monin, B., \& Miller, D. T. (2001). Moral credentials and the expression of prejudice. Journal of Personality and Social Psychology, 81(1), 33-43.

Paulhus, D.L. (1984). Two-component models of socially desirable responding. Journal of Personality and Social Psychology, 46, 598-609.

Paulhus, D. L. (1991a). Measurement and control of response bias. In J. R Robinson, R Shaver, \& L. S. Wrightsman (Eds.), Measures of personality and social psychological attitudes. San Diego: Academic Press, 15-79.

Paulhus, D. L. (1991b). Enhancement and denial in socially desirable responding. Journal of Personality and Social Psychology, 60, 307-317.

Pruckner, G., \& Sausgruber, R. (2006). Trust on the streets: A natural field experiment on newspaper purchasing. University of Copenhagen. Department of Economics (formerly Institute of Economics).

Ritov, I., \& Baron, J. (1990). Reluctance to vaccinate: Omission bias and ambiguity. Journal of Behavioral Decision Making, 3, 263-277.

Rogers, C. (1959). A Theory of Therapy, Personality and Interpersonal Relationships as Developed in the Client-centered Framework. In (ed.) S. Koch, Psychology: A Study of a Science. Vol. 3: Formulations of the Person and the Social Context. New York: McGraw Hill.

Rosenberg, M. (1979). Conceiving the self. New York: Basic Books.

Ross, M., McFarland, C., Conway, M., \& Zanna M. (1983). The reciprocal relation between attitudes and behavioral recall: Committing people to newly formed attitudes. Journal of Personality and Social Psychology, 45, 257-267.

Rozin, P., \& Royzman, E. B. (2001). Negativity bias, negativity dominance, and contagion. Personality and Social Psychology Review, 5, 296-320. 
Sachdeva, S., Iliev, R., \& Medin, D. L. (2009). Sinning saints and saintly sinners: The paradox of moral self-regulation. Psychological Science, 20, 523-528.

Sanitioso, R., Kunda, Z., \& Fong, J. T. (1990). Motivated recruitment of autobiographical memories. Journal of Personality and Social Psychology, 59, 229-241.

Schlenker, B. R. (1980). Impression management: The self concept, social identity and interpersonal relations. Monterey, CA: Brooks/Cole.

Shalvi, S., Dana, J., Handgraaf, M.J.J \& De Dreu, C.K.W. (2011). Justified Ethicality: Observing Desired Counterfactuals Modifies Ethical Perceptions and Behavior. Organizational Behavior and Human Decision Processes, 115, 181-190.

Sherman, S.J., \& Gorkin, L. (1980). Attitude bolstering when behavior is inconsistent with central attitudes. Journal of Experimental Social Psychology, 16, 388-403.

Shu, L., \& Gino, F. (2012). Sweeping dishonesty under the rug: How unethical actions lead to moral forgetting. Journal of Personality and Social Psychology.

Shu, L. L., Gino, F., \& Bazerman, M. H. (2011). Dishonest deed, clear conscience: When cheating leads to moral disengagement and motivated forgetting. Personality and Social Psychology Bulletin, 37(4), 330-349.

Spencer, S. J., Josephs, R. A., \& Steele, C. M. (1993). Low self-esteem: The uphill struggle for self-integrity. In R. Baumeister (Ed.), Self-Esteem: The Puzzle of Low Self-Regard. New York: Plenum.

Spranca, M., Minsk, E., \& Baron, J. (1991). Omission and commission in judgment and choice. Journal of Experimental Social Psychology, 27, 76-105.

Steele, C. M. (1988). The psychology of self-affirmation: Sustaining the integrity of the self. In L. Berkowitz (Ed.), Advances in Experimental Social Psychology (pp. 261-302). San Diego, CA: Academic Press.

Stix, G. (2009). Turbocharging the brain. Scientific American, 301, 46-55. 
Stone, J. \& Cooper, J. (2001). A self-standards model of cognitive dissonance. Journal of Experimental Social Psychology,37, 228-243.

Tajfel, H. (1982). Social psychology of intergroup relations. Annual Review of Psychology, $33,1-39$.

Tenbrunsel, A. E., Diekmann, K.A., Wade-Benzoni, K.A., \& Bazerman, M.H. (2010). The ethical mirage: A temporal explanation as to why we are not as ethical as we think we are. Research in Organizational Behavior, 30, 153-173.

Tenbrunsel, A. E., \& Messick, D. M. (2004). Ethical fading: The role of self deception in unethical behavior. Social Justice Research, 17(2), 223-236.

Tetlock, P. E. (1985). Accountability: A social check on the fundamental attribution error. Social Psychology Quarterly, 48, 227-236

Tetlock, P. E., Kristel, O. Elson, B. Green, M. \& Lerner, J. S. (2000). The psychology of the unthinkable: Taboo trade-offs, forbidden base rates, and heretical counterfactuals. Journal of Personality and Social Psychology, 78, 853-870.

Thibodeau, R., \& Aronson, E. (1992). Taking a closer look: Reasserting the role of the self concept in dissonance theory. Personality and Social Psychology Bulletin, 18(5), $591-602$.

Viswesvaran, Ch., \& Deshpande S. P. (1996). Ethics, success, and job satisfaction: A test of dissonance theory in India. Journal of Business Ethics, 15, 1065-1069.

Wicklund, R. A., \& Brehm, J. W. (1976). Perspectives on cognitive dissonance. Hillsdale, NJ: Erlbaum.

Wicklund, R. A., \& Gollwitzer, P. M. (1981). Symbolic self-completion, attempted influence, and self-deprecation. Basic and Applied Social Psychology, 2, 89-114. 


\section{$\underline{\text { Endnotes }}$}

${ }^{1}$ The framework of cognitive dissonance has been applied to various contexts, including employee commitment, performance and satisfaction (e.g.,Viswesvaran \& Deshpande, 1996), ethical consumption (e.g., Chatzidakis, Hibbert, Mittusis, \& Smith, 2004), and to dilemmas surrounding prescription of cognitive enhancing treatments for ADHD patients (Stix, 2009). Yet, the term "ethical dissonance" is rarely used and is loosely defined.

${ }^{2}$ Sherman and Gorkin (1980) first measured participants' feminist attitude and then induced cognitive dissonance with a tricky sex-role riddle (in which the solution depends on the realization that a surgeon can be female rather than male and failure implies sexism). Participants in the control condition solved a neutral riddle. Later on, all participants were presented with a sex discrimination legal case in which a woman claimed she had been turned down for a position because of her gender. Focusing the analysis on participants who failed to solve the sex-role riddle (i.e., experienced dissonance), the findings indicated a positive correlation between the initial score on feminism and the tendency to side with the plaintiff $(\mathrm{r}=.71)$. That is, as the dissonance was more intense, participants bolstered their feminist attitude. The same correlation was significantly lower $(\mathrm{r}=.21)$ for participants who failed to solve the neutral riddle.

${ }^{3}$ We decided for three main reasons to inform our participants in advance that they would shred their written reports at the end of the study. First, this procedure protected participants' right to privacy. Second, we believed this procedure would encourage the recall of significant personal incidents. Third, and most important, we kept the manipulation at the intraindividual level and eliminated potential demand characteristics of face-saving, compensation, or impression management. Outcomes of deliberate impression management and false self-presentation are thus interpreted as responses to an internal tension rather than to external pressures or fear of judgment. The main disadvantage of this procedure is that 
unlike the work of Jordan et al. (2011), we cannot code the reported incidents and their magnitude.

${ }^{4}$ Social Desirability Responding (SDR) is defined as the tendency of respondents to provide answers that make them look good. Measuring this tendency initially aimed to provide tools controlling for this bias in diagnostic psychometric scales. Factor analyses consistently indicated SDR scales were loaded on two main factors. Paulhus (1984) provided evidence that one factor represents an unconscious self-deceptive positivity bias, whereas the second factor represents a deliberate effort of impression management and false presentation. The Balanced Inventory of Desirable Responding (BIDR, Paulhus, 1984) measures these factors with a self-deceptive enhancement scale (SDE) and an impression-management scale (IM). ${ }^{5}$ For robustness, we conducted additional analyses in which we selected only 16 items of the self-enhancement scale based on a factor analysis to increase the reliability of the measure $(\alpha=.71)$. Even with this improved measure, the results did not change in nature or in significance.

${ }^{6}$ One may argue that recollections of justifiable and/or visible misconducts involved milder incidents than those recalled in the standard undeniable and hidden misconduct. Thus a correspondence exists between the severity of ethical misconduct and its justifiability or visibility. This confound is at the heart of the distinction between minor cases of ethical dissonance that can be solved with bounded ethicality or creative rationalizations of one's own behavior and stronger cases of ethical dissonance requiring the distancing mechanism we identified here. 
Tables

Table 1

Descriptive statistics (means and 95\% confidence intervals of standard deviations), Study 1

\begin{tabular}{lcccc}
\hline & Self-esteem & $\begin{array}{c}\text { Likelihood of } \\
\text { hiring }\end{array}$ & $\begin{array}{c}\text { Loyalty to } \\
\text { the company }\end{array}$ & $\begin{array}{c}\text { Honesty on } \\
\text { the job }\end{array}$ \\
\cline { 2 - 5 } Ethical dissonance & 3.92 & 2.06 & 1.47 & 1.50 \\
& $(1.10-1.77)$ & $(0.75-1.20)$ & $(0.57-0.91)$ & $(0.57-0.91)$ \\
Worthy conduct & 5.78 & 3.41 & 2.09 & 2.15 \\
& $(0.45-0.74)$ & $(1.19-1.95)$ & $(0.87-1.42)$ & $(0.87-1.42)$ \\
Neutral event & 5.08 & 3.71 & 2.06 & 2.20 \\
& $(1.01-1.64)$ & $(1.24-2.00)$ & $(0.83-1.35)$ & $(1.04-1.68)$ \\
Negative event & 5.00 & 3.53 & 2.14 & 2.28 \\
& $(0.78-1.25)$ & $(0.98-1.58)$ & $(0.92-1.47)$ & $(1.04-1.67)$ \\
\hline
\end{tabular}

Table 2

Descriptive statistics (means and 95\% confidence intervals of standard deviations), Study 2

\begin{tabular}{lcccc}
\hline & Self-esteem & $\begin{array}{c}\text { Judgments of } \\
\text { unethicality } \\
\text { of behaviors }\end{array}$ & $\begin{array}{c}\text { Likelihood of } \\
\text { self to } \\
\text { behave } \\
\text { unethically }\end{array}$ & $\begin{array}{c}\text { Likelihood to } \\
\text { recommend a friend to } \\
\text { behave unethically }\end{array}$ \\
\cline { 2 - 5 } Ethical dissonance & 3.42 & 5.02 & 2.76 & 3.00 \\
Worthy conduct & $(1.23-1.79)$ & $(1.14-1.66)$ & $(1.33-1.93)$ & $(1.27-1.85)$ \\
Neutral event & 5.74 & 4.25 & 3.68 & 4.08 \\
& $(0.43-0.64)$ & $(1.19-1.78)$ & $(1.25-1.87)$ & $(1.28-1.91)$ \\
& 4.96 & 4.11 & 3.81 & 4.16 \\
\hline
\end{tabular}


Table 3

Descriptive statistics (means and 95\% confidence intervals of standard deviations), Study 4

\begin{tabular}{|c|c|c|c|c|c|c|c|c|}
\hline & Self-esteem & $\begin{array}{l}\text { Impression } \\
\text { management }\end{array}$ & $\begin{array}{l}\text { Self-deceptive } \\
\text { enhancement }\end{array}$ & $\begin{array}{l}\text { Behavior is } \\
\text { wrong }\end{array}$ & $\begin{array}{c}\text { Actor is } \\
\text { honest }\end{array}$ & $\begin{array}{l}\text { Self behave } \\
\text { unethically }\end{array}$ & $\begin{array}{c}\text { Behavior is } \\
\text { due to } \\
\text { situation }\end{array}$ & $\begin{array}{c}\text { Behavior is } \\
\text { due to } \\
\text { personality }\end{array}$ \\
\hline $\begin{array}{l}\text { Self } \\
\text { (ethical dissonance) }\end{array}$ & $\begin{array}{c}4.03 \\
(1.24-1.96)\end{array}$ & $\begin{array}{c}4.41 \\
(0.87-1.38)\end{array}$ & $\begin{array}{c}4.28 \\
(0.51-0.81)\end{array}$ & $\begin{array}{c}6.62 \\
(1.22-1.92)\end{array}$ & $\begin{array}{c}3.31 \\
(0.94-1.48)\end{array}$ & $\begin{array}{c}2.96 \\
(1.23-1.93)\end{array}$ & $\begin{array}{c}5.28 \\
(1.34-2.11)\end{array}$ & $\begin{array}{c}6.55 \\
(0.99-1.56)\end{array}$ \\
\hline Close-other & $\begin{array}{c}4.82 \\
(1.19-1.70)\end{array}$ & $\begin{array}{c}3.97 \\
(0.93-1.32)\end{array}$ & $\begin{array}{c}4.26 \\
(0.61-0.87)\end{array}$ & $\begin{array}{c}5.89 \\
(1.40-2.00)\end{array}$ & $\begin{array}{c}4.03 \\
(1.22-1.73)\end{array}$ & $\begin{array}{c}4.11 \\
(1.80-2.57)\end{array}$ & $\begin{array}{c}6.04 \\
(1.39-1.98)\end{array}$ & $\begin{array}{c}5.91 \\
(1.37-1.95)\end{array}$ \\
\hline Distant-other & $\begin{array}{c}5.23 \\
(1.05-1.54) \\
\end{array}$ & $\begin{array}{c}3.81 \\
(0.80-1.17) \\
\end{array}$ & $\begin{array}{c}4.21 \\
(0.54-0.79) \\
\end{array}$ & $\begin{array}{c}5.60 \\
(1.75-2.54) \\
\end{array}$ & $\begin{array}{c}4.30 \\
(1.39-2.03) \\
\end{array}$ & $\begin{array}{c}4.41 \\
(2.12-3.09) \\
\end{array}$ & $\begin{array}{c}6.07 \\
(1.47-2.14) \\
\end{array}$ & $\begin{array}{c}5.67 \\
(1.64-2.38) \\
\end{array}$ \\
\hline
\end{tabular}


Table 4

Descriptive statistics (means and 95\% confidence intervals of standard deviations), Study 5

\begin{tabular}{lcccccc}
\hline & $\begin{array}{c}\text { Self- } \\
\text { esteem }\end{array}$ & $\begin{array}{c}\text { MASC } \\
\text { daily } \\
\text { misconduc } \\
\mathrm{t}\end{array}$ & $\begin{array}{c}\text { MASC } \\
\text { common } \\
\text { excuses }\end{array}$ & $\begin{array}{c}\text { MASC } \\
\text { business } \\
\text { dilemmas }\end{array}$ & $\begin{array}{c}\text { BIDR } \\
\text { SDE }\end{array}$ & $\begin{array}{c}\text { BIDR } \\
\text { IM }\end{array}$ \\
\cline { 2 - 7 } Ethical dissonance & 4.65 & 4.04 & 4.62 & 6.07 & 4.20 & 4.35 \\
Personal failure & $(1.05-1.54)$ & $(0.86-1.26)$ & $(0.65-0.95)$ & $(0.57-0.84)$ & $(0.67-0.99)$ & $(0.96-1.41)$ \\
& $(1.17-1.78)$ & 3.18 & 4.13 & 5.46 & 4.08 & 3.94 \\
Cognitive dissonance & $(0.80-1.21)$ & $(0.58-0.88)$ & $(0.86-1.31)$ & $(0.46-0.71)$ & $(0.65-0.98)$ \\
& $(0.95-1.39)$ & $(0.97-1.41)$ & $(0.89-1.29)$ & $(0.82-1.19)$ & $(0.52-0.76)$ & $(0.78-1.13)$ \\
\hline
\end{tabular}

Table 5

Means (and 95\% confidence intervals of standard deviations) of main measures by conditions, Study 6

\begin{tabular}{|c|c|c|c|c|c|c|c|c|}
\hline \multirow[b]{3}{*}{$\begin{array}{l}\text { Justifiable } \\
\text { behavior }\end{array}$} & \multicolumn{2}{|c|}{ Self-esteem score } & \multicolumn{2}{|c|}{$\begin{array}{l}\text { Likelihood of } \\
\text { daily misconducts }\end{array}$} & \multicolumn{2}{|c|}{$\begin{array}{l}\text { Likelihood of } \\
\text { common excuses } \\
\text { being lies }\end{array}$} & \multicolumn{2}{|c|}{$\begin{array}{l}\text { Likelihood of } \\
\text { actor behaving } \\
\text { dishonestly in } \\
\text { given scenario }\end{array}$} \\
\hline & Hidden & Visible & Hidden & Visible & Hidden & Visible & Hidden & Visible \\
\hline & $\begin{array}{l}5.11 \\
(0.91- \\
1.46)\end{array}$ & $\begin{array}{l}5.02 \\
(0.96- \\
1.61)\end{array}$ & $\begin{array}{l}4.69 \\
(0.91- \\
1.46)\end{array}$ & $\begin{array}{c}4.56 \\
(0.72- \\
1.22)\end{array}$ & $\begin{array}{l}4.12 \\
(0.74- \\
1.19)\end{array}$ & $\begin{array}{c}4.08 \\
(0.60- \\
1.01)\end{array}$ & $\begin{array}{c}5.44 \\
(0.90- \\
1.45)\end{array}$ & $\begin{array}{c}5.30 \\
(0.76- \\
1.28)\end{array}$ \\
\hline $\begin{array}{l}\text { Undeniably } \\
\text { wrong } \\
\text { behavior }\end{array}$ & $\begin{array}{c}4.06 \\
(0.51- \\
0.85)\end{array}$ & $\begin{array}{l}4.92 \\
(0.45- \\
0.77)\end{array}$ & $\begin{array}{c}5.44 \\
(0.60- \\
1.00)\end{array}$ & $\begin{array}{c}4.45 \\
(0.58- \\
0.98)\end{array}$ & $\begin{array}{l}4.88 \\
(0.45- \\
0.74)\end{array}$ & $\begin{array}{c}3.87 \\
(0.52- \\
0.87)\end{array}$ & $\begin{array}{c}6.37 \\
(0.57- \\
0.94)\end{array}$ & $\begin{array}{c}5.57 \\
(0.50- \\
0.85)\end{array}$ \\
\hline
\end{tabular}

